\title{
Opening Mechanism of Closed Graphitized Tips via Low-Temperature Surface Fluorination
}

\section{Interest for Electrochemical Storage}

\author{
H. Groult, ${ }^{\mathrm{a}, *, \mathrm{z}}$ T. Nakajima, ${ }^{\mathrm{b}, *}$ A. Tressaud, ${ }^{\mathrm{c}}$ S. Shibata, ${ }^{\mathrm{b}}$ E. Durand, \\ L. Perrigaud, ${ }^{\mathrm{a}}$ and F. Warmont ${ }^{\mathrm{d}}$
}

\author{
${ }^{a}$ Université Pierre et Marie Curie-Paris 6, UMR 7612 CNRS, Paris, F-75005 France \\ ${ }^{b}$ Department of Applied Chemistry, Aichi Institute of Technology, Yakusa-cho, \\ Toyota-shi 470-0392, Japan \\ ${ }^{c}$ ICMCB-CNRS, Université Bordeaux 1, 33608 Pessac Cedex, France \\ ${ }^{d}$ CRMD - UMR 6619 CNRS, 45071 Orléans Cedex 2, France
}

\begin{abstract}
When treated at high temperatures, petroleum coke materials exhibit structures which are formed of graphitized closed tips. The external surface of these materials is mostly formed of hemispherical tips similar to those found in carbon nanotubes. By low-temperature fluorination using $\mathrm{CF}_{4}$ radio-frequency plasmas, an opening mechanism of the closed tips occurs, thus allowing a drastic increase of possible intercalation into the structure. The interest for $\mathrm{Li}^{+}$storage in $\mathrm{Li}$-ion batteries has been demonstrated by capacity measurements which show an enhancement of the $\mathrm{Li}^{+}$capacity retention into the host materials.
\end{abstract}

The use of carbon electrodes in various electrochemical processes is strongly related to their structural properties. Thus, gas $\left(\mathrm{H}_{2}\right)$ or ions $\left(\mathrm{Li}^{+}\right)$storage into graphite-based materials is extensively studied. Indeed, Li-ion secondary batteries are nowadays used at any moment of everyday life in portable telephones, video cameras, personal computers, etc. The need for higher performances is, however, still required in order to increase both charge capacity and cycle life. In these systems, the cathode part generally consists of transition metal oxides and the electrolyte is formed of mixtures of organic solvents with a $\mathrm{Li}^{+}$ion carrier such as $\mathrm{LiPF}_{6}$. Numerous types of carbon-based compounds, including graphitized and nongraphitized materials, have been screened in order to select the most suitable type of anodic material. In parallel, several studies have been devoted to the modification of existing materials to improve their electrochemical performances vs $\mathrm{Li}$ insertion/extraction. For instance, thermal treatments and surface modification processes have been applied to the carbon-based materials to improve their cycling characteristics. Thus, surface oxidation of mesocarbon microbeads improved the intercalation kinetics by removing the surface skin which hinders the Li-ion intercalation. ${ }^{1}$ In the case of graphitic materials, fluorination has also been shown to enlarge the surface area of graphitic anodes and to change the pore volume distribution with a subsequent increase of capacities, which could eventually exceed the theoretical value of graphite. ${ }^{2,3}$

Concerning the external structure of the carbon-based materials, it has been shown that the surface of the particles of highly graphitized materials consisted of closed-edged structures similar to nanotube tips. The formation mechanism of these loops has been studied using molecular dynamics simulations and compared with high resolution transmission electron microscopy (TEM) observations in the case of mesophase pitch graphitized at $3000^{\circ} \mathrm{C}$. Large discharge and small irreversible capacity could be obtained in these materials through suitable high-temperature pretreatment. ${ }^{4}$ Molecular dynamics simulations have also shown that open tips of single wall nanotubes (SWNTs) spontaneously close into hemispheric domes at 2000-3000 K. ${ }^{5,6}$ A recent field emission study has shown that SWNT tips can be opened under high emission current and closed again when the current is decreased at the estimated temperature of $1600 \mathrm{~K}^{7,8}$ Similar opening has been obtained through a drastic chemical treatment by $\mathrm{NaOH}$ at $600^{\circ} \mathrm{C} .^{9}$

Much information has been obtained on the fluorination mechanism of fullerenes and carbon nanotubes (CNTs) since their

${ }^{\mathrm{z}}$ E-mail: groult@ccr.jussieu.fr discovery. ${ }^{10,11}$ In particular, the dependence of the selectivity of the fluorination with the nature of the endings has been pointed out in SWNTs. ${ }^{12}$ In open tubes, since fluorine can access to the interior part, the fluorination is concentrated in limited (tip) sections, whereas in closed tubes a larger part of the exterior side of the CNT is attacked for heavier fluorination conditions.

Here, we describe the opening mechanism of closed tips forming the extreme surface of graphitized petroleum cokes (PC) which is observed at low temperature when these materials are submitted to rf plasma fluorination. TEM images of rf plasma fluorinated graphitized pyrocarbons are also compared with those obtained with samples treated with $\mathrm{F}_{2}$ gas.

\section{Experimental}

Radio-frequency (rf) plasma fluorination technique is currently used to modify drastically at low temperatures the surface of various types of materials, including metals, ceramics, carbons, and polymers. ${ }^{13}$ Different types of fluorinated gases can be used for such purpose including $\mathrm{CF}_{4}, \mathrm{CHF}_{3}, \mathrm{C}_{4} \mathrm{~F}_{8}, \mathrm{SF}_{6}$. Among the main advantages of the technique, it can be quoted that $(i)$ the reactions are limited to the utmost surface of the treated material, (ii) the samples are not heated since the fluorination takes place in most cases at room temperature. It has been shown recently that graphite samples exhibit higher capacities after a surface treatment with $\mathrm{CF}_{4}$ in $\mathrm{rf}$ plasma conditions. ${ }^{14,15}$ When these materials are used as anode in Li-ion battery, these capacities may exceed the theoretical capacity of graphite. ${ }^{3}$ Additionally, $\mathrm{CF}_{4}$ plasmas have been shown to modify the field-emission properties of aligned multiwall CNT. ${ }^{16}$

In this work, results obtained with petroleum coke samples, pretreated at $2800^{\circ} \mathrm{C}$ (PC-2800), provided by Toyo Tanso Co. are presented. Surface fluorination experiments were carried out at low temperature in a fluorinated plasma obtained from $\mathrm{CF}_{4}$ gas excited by a rf source at $13.56 \mathrm{MHz}$. A primary vacuum was obtained by a $40 \mathrm{~m}^{3} \mathrm{~h}^{-1}$ pump equipped with a liquid nitrogen condenser in order to trap the residual gases. The reactive gas was dissociated by electron impacts occurring between the two electrodes and subsequently neutral species and $\mathrm{F}^{*}$ radicals diffused to the sample. The plasma reaction was carried out at room temperature, or at temperatures not exceeding $90^{\circ} \mathrm{C}$. Several experimental parameters could be adjusted, namely, the inlet gas flow: $8 \mathrm{~cm}^{3} \mathrm{~min}^{-1}$, the total pressure: $\approx 100$ mTorr, the $\mathrm{rf}$ power: $80 \mathrm{~W}$, and the reaction duration: $15 \mathrm{~min}$. It has been previously shown that, in such conditions, the $\mathrm{CF}_{4}$ treatment corresponds to a reactive etching of the surface of carbon materials, with formation of covalent $\mathrm{C}-\mathrm{F}_{n}$ bonds. ${ }^{13}$ The surface analyses of the materials were carried out using electron 


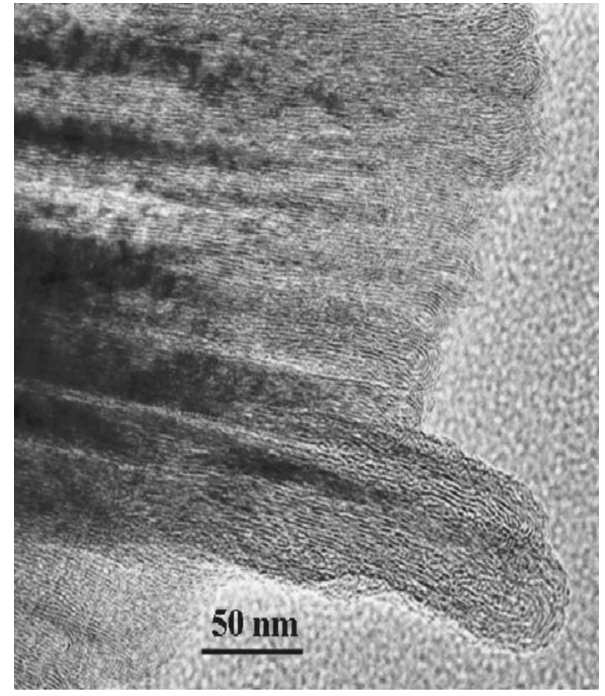

(a)

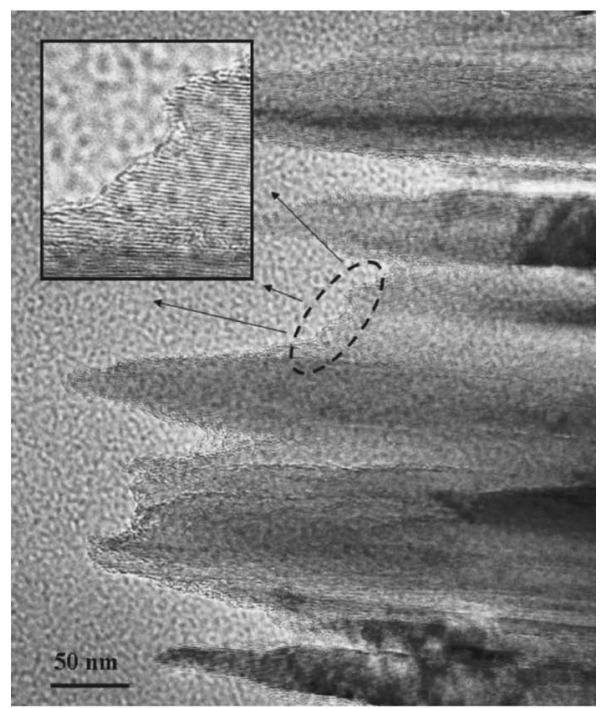

(b)

Figure 1. TEM photographs of external edges of (a) pristine petroleum coke materials high-temperature treated at $2800^{\circ} \mathrm{C}$; (b) $\mathrm{PC}-2800$ after a $15 \mathrm{~min}$ rf-plasma fluorination at $90^{\circ} \mathrm{C}$.

probe microanalysis (EPMA) with a Cameca SX 100 microprobe with 3 WDS spectrometers and X-ray photoelectron spectroscopy (XPS) analysis with VG Escalab 220i XL equipment. Transmission electron micrographs were obtained with a JEOL JEM 100 CX II transmission electron microscope equipped with a JEOL high resolution scanning attachment (STEM-SEM ASID 4D).

Raw and plasma fluorinated PC-2800 samples have been tested as anode materials in Li-ion battery. Charge/discharge cycles were performed at $25^{\circ} \mathrm{C}$ (current rate: $\mathrm{C} / 15$, i.e., discharge in $15 \mathrm{~h}$ ) in $1 \mathrm{~mol} / \mathrm{dm}^{3} \mathrm{LiPF}_{6}-$ ethylene carbonate (EC)/dimethyl carbonate (DMC) (1:1 in vol). The galvanostatic charge-discharge was performed using a potentiostat/galvanostat (VMP Bio-Logic) in the potential range $0.02-2.5 \mathrm{~V}$ at a current density of $60 \mathrm{~mA} / \mathrm{g}$. The error measurements done on the capacity values are $\pm 5 \%$.

\section{Results and Discussion}

Characterization of the materials. - In PC-2800 sample, the value of the $d_{002}$ interlayer distance, determined by X-ray diffraction is $0.3361 \mathrm{~nm}$, confirming the high crystallinity of the material. The

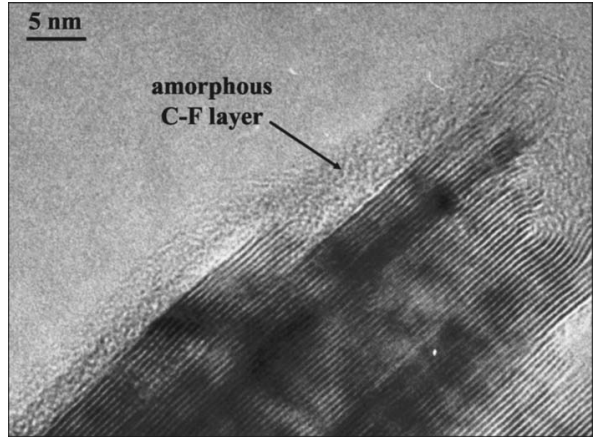

Figure 2. TEM photograph of external edges of petroleum coke materials high-temperature treated at $2800^{\circ} \mathrm{C}$ after a $60 \mathrm{~min}$ rf-plasma fluorination at $90^{\circ} \mathrm{C}$

elemental analysis of the starting petroleum coke has confirmed the presence of oxygen [O: 2.3 atom $\%, \mathrm{C}: 94.8$ atom $\%$, and $\mathrm{H}: 2.9$ atom \%] which is favorable for the closing at high temperatures of the tips of the external carbon edges. ${ }^{17,18}$ Figure 1a shows TEM photo of the external edges of PC-2800 particles. The surface is formed of graphitized closed tips. One may notice that, in contrast with mutliwall carbon nanotubes (MWCNTs), the present structure does not present a central hole. Nevertheless, as for MWCNTs, they exhibit a hemispherical morphology at the end of the tips. These observations are in good agreement with those previously published on ex-mesophase pitch carbons graphitized at $3000^{\circ} \mathrm{C}{ }^{4}$ Molecular dynamics simulations had shown that in the bent parts of the terminal loops, some six-membered carbon rings are transformed into five-membered ones, thus weakening the cohesion strength of the final endings.

For short plasma durations, i.e., $15 \mathrm{~min}, \mathrm{~F}^{*}$ radicals which are the most active species of the $\mathrm{CF}_{4}$ plasma, react with the external closed hemispheres and destroy the most brittle part of the tips, yielding an opening of these tips. This process results in a very regular etching of the surface, as demonstrated in Fig. 1b. Traces of fluorine only were detected by EPMA, confirming the limitation of fluorination effects to the outermost surface. Quantitative XPS data lead to an amount of surface fluorine of about 7 atom $\%$. The position of the F 1s peak, with a major component at $687.5 \mathrm{eV}$, is in good agreement with the covalent nature of $\mathrm{C}-\mathrm{F}_{n}$ bonds. These results confirm that in the $\mathrm{C}-\mathrm{F}$ bonds present at the surface, the electronic configuration of $s p^{2}$ carbon has been transformed into an $s p^{3}$ hybridization, as in most fluorinated carbon materials, ${ }^{13}$ including CNTs. ${ }^{19}$ In addition, it can be noted that the amount of surface fluorine is much lower than that observed in the case of fluorination involving elemental $\mathrm{F}_{2}$. For longer plasma durations at $T=90^{\circ} \mathrm{C}$, an amorphous fluorocarbon skin is formed onto the external surface of the materials (Fig. 2). These observations show clearly that the closed tips present at the surface of high-temperature graphitized materials can be uniformly opened at room temperature, or in any cases at temperatures lower than $90^{\circ} \mathrm{C}$, by plasma fluorination.

Study of the $\mathrm{Li}^{+}$insertion/extraction.- No difference was pointed out between the raw materials and the fluorinated samples on the shape of the chronopotentiograms recorded in $1 \mathrm{M} \mathrm{LiPF}_{6}-\mathrm{EC} / \mathrm{DMC}$. For instance, the first ten charge/discharge cycles obtained for sample fluorinated at $90^{\circ} \mathrm{C}$ during $1 \mathrm{~h}$ are given in Fig. 3. It reveals the formation of the solid electrolyte interface (SEI) layer at around $0.7 \mathrm{~V}$ vs $\mathrm{Li} / \mathrm{Li}^{+}$due to the reduction of EC which gives rise to an irreversible capacity (Table I): as shown in this table, the irreversible capacity values are lower than those observed for the raw material for short fluorination durations. This effect can be attributed to the modification of the surface composition of the starting materials, by removing from the surface the $\mathrm{C}-\mathrm{H}$ and $\mathrm{C}-\mathrm{O}$ bonds involved in the formation of the SEI layer. In other words, the cleaning of the surface induces a limitation of the elec- 


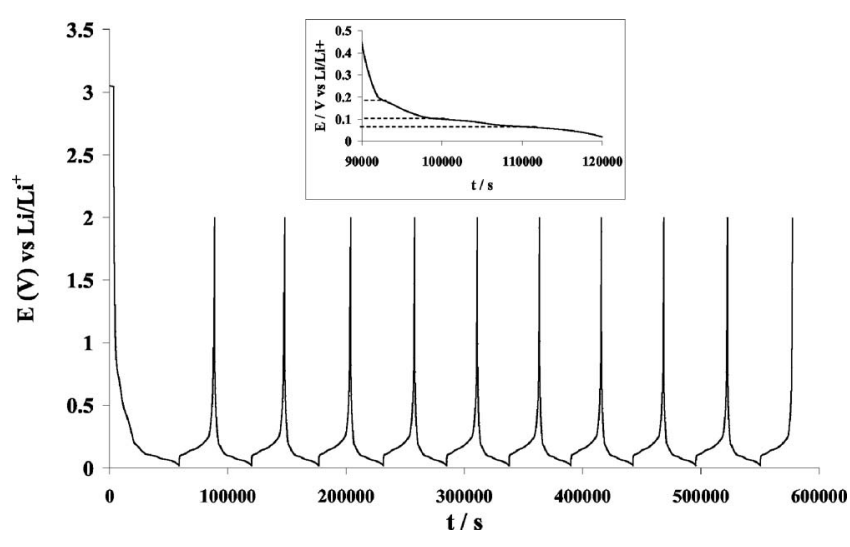

Figure 3. First ten charge/discharge cycles obtained in $1 \mathrm{M} \mathrm{LiPF}_{6}-\mathrm{EC}: \mathrm{DMC}$ (1:1) with PC-2800 fluorinated under $\mathrm{CF}_{4}$ at $90^{\circ} \mathrm{C}$ for 15 min. Rate: $\mathrm{C} / 15$. An expanded view between 0 and $0.5 \mathrm{~V}$ vs $\mathrm{Li} / \mathrm{Li}^{+}$is given in the inset of the figure.

trolyte decomposition, i.e., a decrease of the irreversible capacity values. The voltage profiles between 0.4 and $0.02 \mathrm{~V}$ exhibit several plateaus (inset of Fig. 3) assigned to the coexistence of two-phase regions caused by the stage transformations of lithium-GIC. ${ }^{15,20-26}$ The variation of the reversible capacity, $Q_{\text {rev. }}$, vs fluorination temperature after subsequent charge/discharge cycles is given in Fig. 4. The fluorination at $90^{\circ} \mathrm{C}$ during $15 \mathrm{~min}$ leads to a significant increase of the reversible capacity. After ten cycles, $Q_{\text {rev. }}$ is equal to $244 \mathrm{~m} \mathrm{Ah} / \mathrm{g}$ with respect to $192 \mathrm{~m} \mathrm{Ah/g}$ for the raw PC-2800. This result indicates that after surface fluorination using $\mathrm{CF}_{4}$ radiofrequency plasmas during $15 \mathrm{~min}$ at $90^{\circ} \mathrm{C}$, the capacity retention of $\mathrm{Li}$ into the host structure of PC2800 is significantly increased. The determination of the Brunauer-Emmett-Teller surface areas for these two samples (before and after fluorination) gives rise rather to a similar value of about $2.4 \pm 0.2 \mathrm{~m}^{2} / \mathrm{g} .{ }^{27}$ In contrast, Raman spectroscopy reveals that the ratio of the intensity of the $\mathrm{D}$ band $\left(\mathrm{A}_{1 \mathrm{~g}}\right.$ vibration mode in the disordered region of carbon materials or edge plane of powdery carbon) to the intensity of the $\mathrm{G}$ band (assigned to the $\mathrm{E}_{2 \mathrm{~g}}^{2}$ carbon-carbon stretching mode) which indicates the degree of surface disordering of the carbon surface, slightly increased from about 0.1 for the nonfluorinated powder to about 0.5 for the sample fluorinated at $90^{\circ} \mathrm{C}$ during $15 \mathrm{~min}$. In other words, short plasma
Table I. Data deduced from the galvanostatic charge/discharge curves obtained in $1 \mathrm{M} \mathrm{LiPF}_{6}-\mathrm{EC}: D M C$ (1:1) with raw and fluorinated PC-2800 samples. Values of the irreversible reversible capacity obtained after the first and tenth cycle, respectively. Current density: $60 \mathrm{~mA} / \mathrm{g}$.

\begin{tabular}{lcc} 
Samples & $\begin{array}{c}Q_{\text {irrev }} \\
(\mathrm{m} \mathrm{Ah} / \mathrm{g})\end{array}$ & $\begin{array}{c}Q_{\text {rev }} \\
(\mathrm{m} \mathrm{Ah} / \mathrm{g})\end{array}$ \\
\hline Raw PC2800 & 156 & 192 \\
PC2800- $T_{\mathrm{CF} 4}=25^{\circ} \mathrm{C}-t=15 \mathrm{~min}$ & 134 & 195 \\
PC2800- $T_{\mathrm{CF} 4}=90^{\circ} \mathrm{C}-t=15 \mathrm{~min}$ & 148 & 244 \\
PC2800- $T_{\text {CF4 }}=90^{\circ} \mathrm{C}-t=60 \mathrm{~min}$ & 174 & 188
\end{tabular}

fluorination induces an increase of the surface disordering by destroying and opening the closed edges planes of graphitized petroleum cokes. This effect results in a significant increase of the $\mathrm{Li}$ storage in the fluorinated materials. For the same temperature but longer fluorination duration, an amorphous layer C-F onto the surface was pointed by TEM observations (Fig. 2) and can explain why this beneficial effect is reduced: in that case, the reversible capacity value is lower than that observed for the raw material. So, the parameters of the fluorination procedure (both temperature and duration) must be strictly controlled in order to avoid the formation of large amount of C-F compounds and a partial decomposition of the bulk of the material. Such beneficial effect was recently pointed out by Nakajima et al. ${ }^{28-30}$ using $\mathrm{ClF}_{3}, \mathrm{NF}_{3}, \mathrm{CF}_{4}$ in rf plasma conditions in $1 \mathrm{~mol} / \mathrm{dm}^{3} \quad \mathrm{LiClO}_{4}-\mathrm{EC} /$ diethyl carbonate/propylene carbonate $(1: 1: 1$ in volume) solution. As pointed out in these papers, the reactions of $\mathrm{ClF}_{3}$ and $\mathrm{NF}_{3}$ with carbon materials are radical reactions while the reaction with $\mathrm{F}_{2}$ is an electrophilic reaction yielding fluorinated layers with high disorder. The reaction with $\mathrm{CF}_{4}$ for short duration is analogue to that observed with $\mathrm{NF}_{3}$ and $\mathrm{ClF}_{3}$ gases. By contrast, during the fluorination procedure of PC-2800 under $3 \cdot 10^{4} \mathrm{~Pa} \mathrm{~F}_{2}$ gas during $2 \mathrm{~min}$, a second mechanism may occur, leading to the fragmentation of the tips as shown in Fig. 5. In this case, the active surface is highly increased and so the porous distribution. It should be noted that in both conditions, an amorphous skin is formed onto the external surface of the materials.

\section{Conclusions}

Smooth surface fluorination by $\mathrm{CF}_{4}$ radio-frequency plasma appears to be a promising route to enhance the capability of graphi-

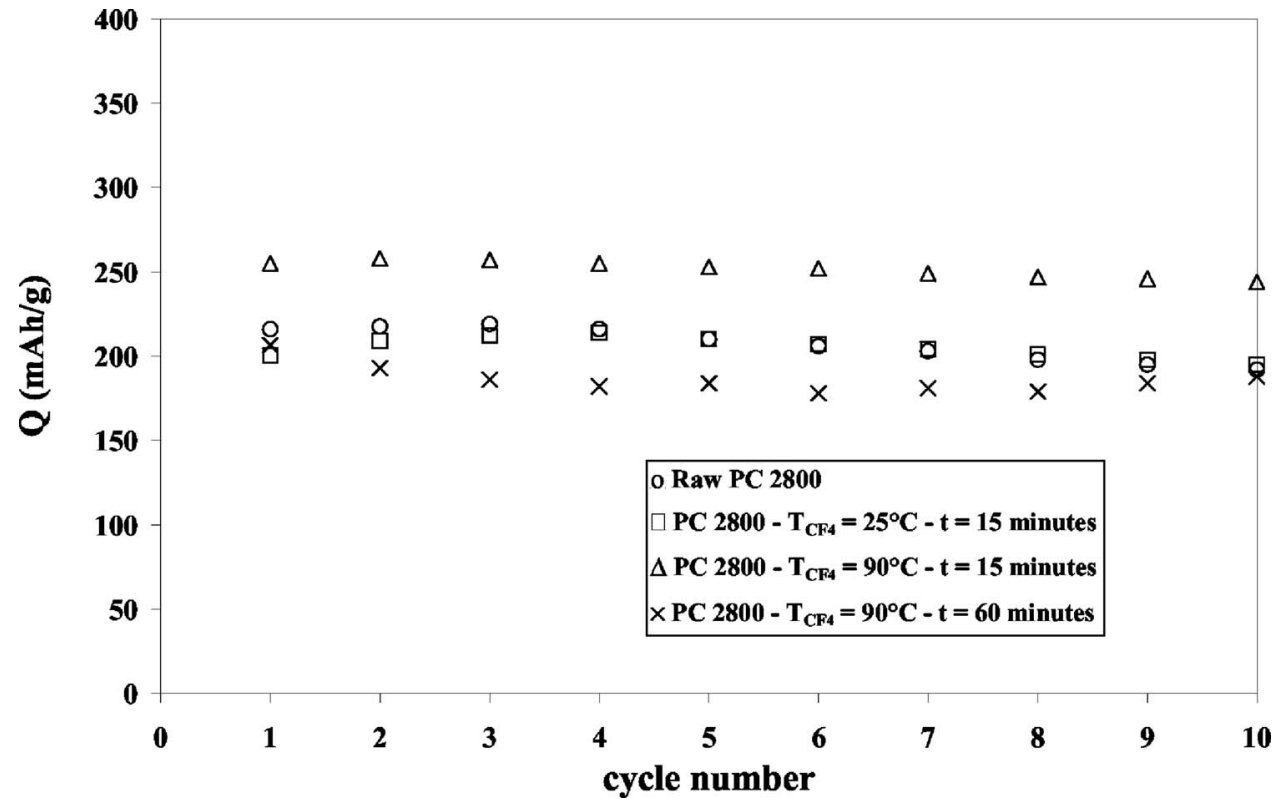

Figure 4. Evolution of the reversible capacity during charge/discharge cycles at C/15 $1 \mathrm{M} \mathrm{LiPF}_{6}$-EC:DMC (1:1) for raw and fluorinated PC-2800. 


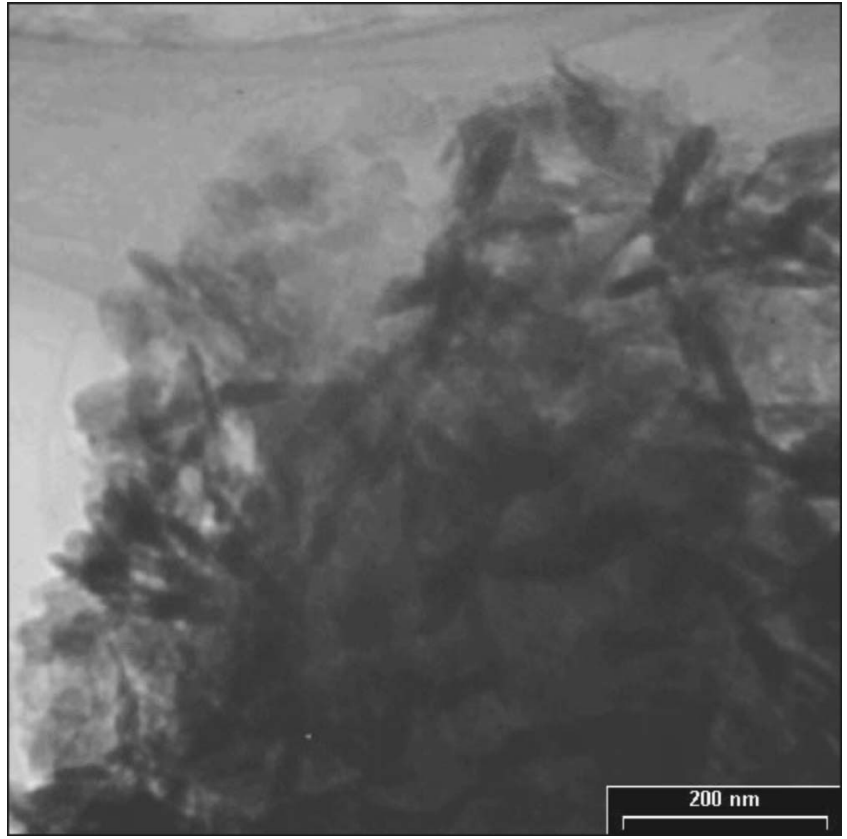

Figure 5. Fragmentation mechanism of PC-2800 treated under $\mathrm{F}_{2}$ gas.

tized materials to store $\mathrm{Li}^{+}$by destroying the most brittle part of the tips and increasing surface disordering. Even if from a practical point of view such materials cannot be considered as the most suitable materials in Li batteries due to the somewhat low Li capacity retention, the beneficial effect of the fluorination process reported in this work could be used for other electrochemical applications. As an example, it should be worthwhile to investigate the potentiality of the opening process of tips or CNT in the case of hydrogen storage.

\section{Acknowledgments}

This work is dedicated to Professor Neil Barlett on the occasion of his 75th birthday.

This work was partially done within the frame of the Frontier Research Project "Materials for the 21st Century - Materials Development for Environment, Energy and Information" from the Ministry of Education, Culture, Sports, Science and Technology, Japan. The authors express their gratitude to M. P. Genevois (UPMC, France) for his technical assistance.
Centre National de la Recherche Scientifique assisted in meeting the publication costs of this article.

\section{References}

1. M. Hara, A. Satoh, N. Tamaki, and T. Ohsaki, Tanso, 165, 261 (1994).

2. T. Nakajima and K. Yanagida, Tanso, 174, 195 (1996).

3. T. Nakajima, M. Koh, R. N. Singh, and M. Shimada, Electrochim. Acta, 44, 2879 (1999).

4. K. Moriguchi, S. Munetoh, M. Abe, M. Yonemura, K. Kamei, A. Shintani, Y. Maehara, A. Omaru, and M. Nagamine, J. Appl. Phys., 88, 6369 (2000).

5. J. C. Charlier, X. Blasé, A. De Vita, and R. Car, Appl. Phys. A, 68, 267 (1999).

6. Van Lier, C. P. Ewels, F. Zuliani, A. De Vita, and J. C. Charlier, J. Phys. Chem. B, 109, 6153 (2005).

7. K. A. Dean and B. R. Chalamala, J. Vac. Sci. Technol. B, 21, 868 (2003).

8. H. Z. Geng, X. B. Zhang, S. H. Mao, A. Kleinhammes, H. Shimoda, Y. Wu, and O Zhou, Chem. Phys. Lett., 399, 109 (2004).

9. E. Raymondo-Pinero, T. Cacciaguerra, P. Simon, and F. Beguin, Chem. Phys. Lett., 412, 184 (2005).

10. H. W. Kroto, J. R. Heath, S. C. O'Brien, R. F. Curl, and R. E. Smalley, Nature (London), 318, 162 (1985)

11. S. Iijima, Nature (London), 354, 56 (1991)

12. S. Kawasaki, K. Komatsu, F. Okino, H. Touhara, and H. Katsura, Phys. Chem. Chem. Phys., 6, 1769 (2004).

13. C. Cardinaud and A. Tressaud, Chap.14, Advanced Inorganic Materials, T. Nakajima, A. Tressaud, B. Žemva, Editors, Elsevier, Amsterdam (2000).

14. T. Nakajima, V. Gupta, Y. Ohzawa, M. Koh, R. N. Singh, A. Tressaud, and E. Durand, J. Power Sources, 104, 108 (2002).

15. T. Nakajima, V. Gupta, Y. Ohzawa, H. Iwata, A. Tressaud, and E. Durand, $J$ Fluorine Chem., 114, 209 (2002).

16. Y. W. Zhu, F. C. Cheong, T. Yu, X. J. Xu, C. T. Lim, J. T. L. Thong, Z. X. Shen, C. K. Ong, Y. J. Liu, A. T. S. Wee, and C. H. Sow, Carbon, 43, 395 (2005).

17. T. Nakajima, J. Li, K. Naga, K. Yoneshima, T. Nakai, and Y. Ohzawa, J. Power Sources, 133, 243 (2004).

18. J. Li, K. Naga, Y. Ohzawa, T. Nakajima, and H. Iwata, J. Fluorine Chem., 126, 1028 (2005).

19. N. O. V. Plank, L. Jiang, and R. Cheung, Appl. Phys. Lett., 83, 2426 (2003).

20. J. R. Dahn, Phys. Rev. B, 44, 9170 (1991).

21. T. Ohzuku, Y. Iwakoshi, and K. Sawai, J. Electrochem. Soc., 140, 2490 (1993).

22. D. Aurbach, Chap. 6, Nonaqueous Electrochemistry, D. Aurbach, Editor, pp. 289409, Dekker, New York (1999).

23. S. Flandrois and B. Simon, Carbon, 37, 165 (1999).

24. H. Groult, B. Kaplan, F. Lantelme, T. Nakajima, V. Gupta, S. Komaba, N. Kumagai, and B. Simon, J. Electrochem. Soc., 150, G67 (2003).

25. Z. Ogumi and M. Inaba, Bull. Chem. Soc. Jpn., 71, 521 (1998).

26. A. Funabiki, M. Inaba, T. Abe, and Z. Ogumi, J. Electrochem. Soc., 146, 2443 (1999).

27. T. Nakajima, S. Shibata, K. Naga, Y. Ohzawa, A. Tressaud, E. Durand, H. Groult, and F. Warrmont, J. Power Sources, 168, 265 (2007).

28. T. Nakajima, K. Naga, Y. Ohzawa, Z. Mazej, B. Žemva, and H. Groult, J. Electrochem. Soc., 154, A347 (2007).

29. K. Naga, T. Nakajima, S. Aimura, Y. Ohzawa, B. Žemva, Z. Mazej, H. Groult, and A. Yoshida, J. Power Sources, 167, 192 (2007).

30. T. Achicha, S. Shibata, T. Nakajima, Y. Ohzawa, A. Tressaud, and E. Durand, $J$. Power Sources, Accepted. 